\title{
CARDIAC BLOOD-FILLED CYST AT THE ATRIALIZED PORTION OF THE RIGHT VENTRICLE IN A PATIENT WITH EBSTEN ANOMALY: A CASE REPORT
}

Smruti Ranjan Mohanty, MCh, Kona Samba Murthy, MCh, Shivaprakasha Krishnanaik, MCh, Ammu Sivaraman, MD, and Kotturathu Mamman Cherian, FRACS, Chennai, India

Blood-filled cysts of heart valves are commonly reported as postmortem findings in infants. They are small, pinhead sized nodules that disappear by the age of 6 months. ${ }^{1}$ Such cysts, although rare in adults, ${ }^{2}$ have been identified in the tricuspid, ${ }^{3}$ mitral, ${ }^{4}$ and pulmonary valves, ${ }^{5}$ but their occurrence in the atrialized part of the ventricle in Ebstein anomaly has not been reported.

We report the successful management of a large bloodfilled cyst at the atrialized portion of the right ventricle in a patient with Ebstein anomaly.

Clinical summary. A 31-year-old woman reported to our cardiac clinic with a 10-year history of palpitations and dys-

From the Institute of Cardiovascular Diseases, Madras Medical Mission, Chennai, India.

Received for publication Feb 17, 2000; accepted for publication Feb $25,2000$.

Address for reprints: Smruti Ranjan Mohanty, MCh, Institute of Cardiovascular Diseases, Madras Medical Mission, 4/A, Dr J. Jayalalitha Nagar, Mogappair, Chennai-600 050, India (E-mail: mmmbits@.vsnl.com).

J Thorac Cardiovasc Surg 2000;120:422-3

Copyright $\odot 2000$ by The American Association for Thoracic Surgery $0022-5223 / 2000 \$ 12.00+0 \quad \mathbf{1 2 / 5 4 / 1 0 6 9 6 9}$

doi: $10.1067 / \mathrm{mtc} .2000 .106969$ pnea on exertion. Cardiac examination revealed a grade $2 / 6$ systolic murmur in the tricuspid area. A chest x-ray film revealed mild cardiomegaly, and she had sinus bradycardia with a rate of 54 beats/min. The echocardiogram showed Ebstein anomaly of the tricuspid valve, a large atrial septal defect with moderate tricuspid regurgitation, and mild right ventricular dysfunction. She was in New York Heart Association class II. Regular follow-up was recommended. At 18 months of follow-up a right bundle branch block developed, and echocardiography showed a mass of $2.2 \times 2.4 \mathrm{~cm}$ at the atrialized part of the right ventricle above the septal leaflet, which was presumed to be a thrombus or vegetation (Fig 1). Three consecutive blood cultures were negative for pathogens, and she was started on a regimen of warfarin and aspirin and was closely observed. The mass increased in size $(2.8 \times 2.8$ $\mathrm{cm})$, despite anticoagulation therapy, and type II atrioventricular dissociation developed over a period of 3 months.

At operation a large $(3 \times 3 \mathrm{~cm})$ encapsulated sessile mass (Fig 2) was found to be arising from the atrialized portion of the right ventricle just above the septal leaflet of the tricuspid valve, which was attached firmly to the underlying endothelium. The tricuspid valve leaflets were severely dysplastic and were not suitable for repair. The mass was carefully excised en toto. The tricuspid valve was excised, ventricular plication

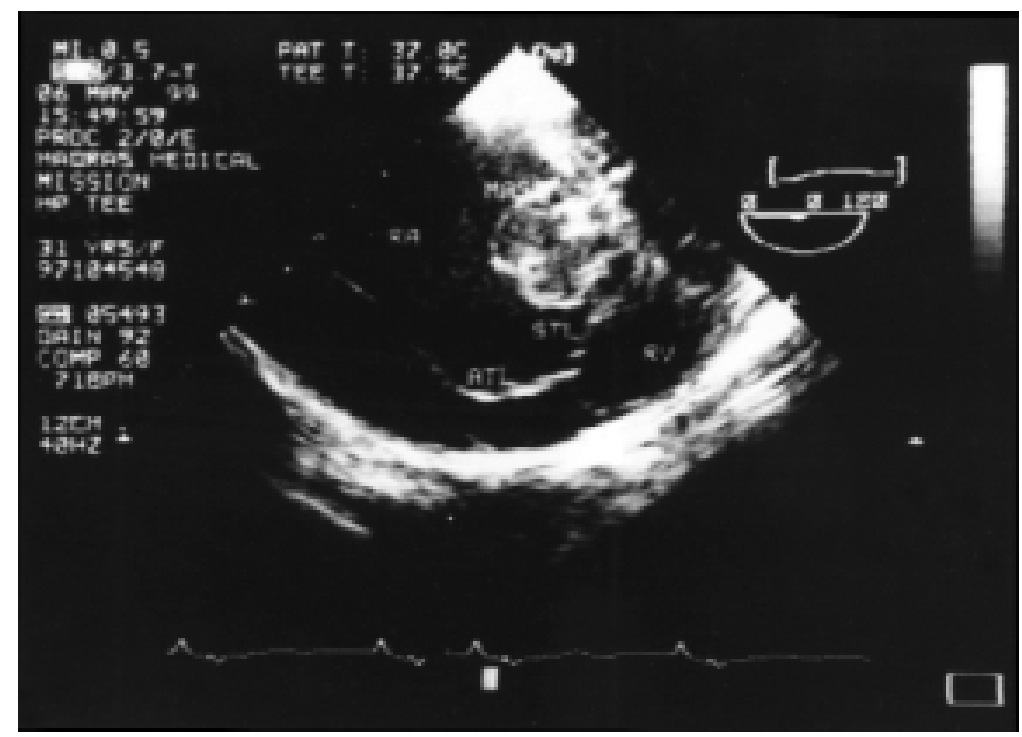

Fig 1. Preoperative transesophageal echocardiogram illustrating the mass in the atrialized portion of right ventricle just above the septal tricuspid leaflet. $R A$, Right atrium; $A T L$, anterior tricuspid leaflet; $S T L$, septal tricuspid leaflet; $R V$, right ventricle; $M A S$, mass. 


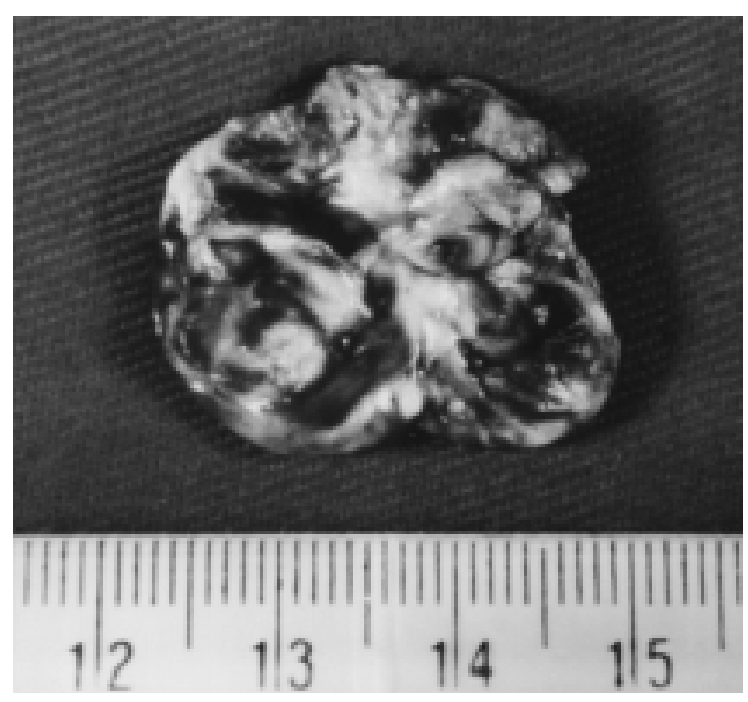

Fig 2. The excised specimen of the blood-filled cyst.

was done, and the tricuspid valve was replaced with a $30-\mathrm{mm}$ Starr-Edwards valve (Baxter Healthcare Corp, Edwards Division, Santa Ana, Calif). The atrial septal defect was closed with a pericardial patch. Postoperatively, she had complete heart block and required a permanent pacemaker.

Histopathologic examination showed a blood-filled cyst lined by endothelium. The space was sinuous and the wall consisted of fibrous tissue with occasional capillaries.

At follow-up 3 months later she was in New York Heart Association class I and there was no recurrence of the cyst.

Discussion. Elsasser first reported on a blood-filled cyst of the heart valve in $1844 .{ }^{1}$ The incidence of such cysts in adulthood is rare, with only a few cases having been reported in the medical literature.

Several theories of origin have been postulated. The cyst may develop when blood enters the crevices on the surface of the valve cusp, or it may be a hematoma of the subvalvular region. ${ }^{1}$ The cyst may also result from heteroplastic changes in the tissue arising from primitive pericardial mesothelium, which participate in the formation of fibrous skeleton of the heart. ${ }^{2}$ Another theory is that in the case of sudden occlusion, such as that caused by inflammation, vagal stimulation, anoxia, and hemorrhagic diathesis, branches of the circulation behave like end arteries and their occlusion leads to hematoma formation. ${ }^{6}$ In this patient the cyst was detected during routine follow-up on medical management. Its size increased, causing partial atrioventricular block over a 3month period. The pathogenesis of this cyst seems to be as per the theory of development of blood-filled cysts advanced by Sakakibara and associates, ${ }^{6}$ because of its typical location and short duration. Although echocardiographically a thinwalled cyst with an echo-free space suggests the diagnosis of a blood-filled cyst, differentiating it from a thrombus or vegetation is practically impossible. Surgical removal of the cardiac blood-filled cyst at the time of diagnosis, even if the patient is free of symptoms, has been suggested. ${ }^{3}$

To our knowledge this is the first report of an acquired blood-filled cyst developing in the atrialized portion of the right ventricle and causing heart block in a patient with Ebstein anomaly. We recommend early excision of the cyst in patients who have complications and even in symptom-free patients to avoid subsequent complications.

\section{REFERENCES}

1. Boyd TAB. Blood cyst on the heart valves of infants. Am J Pathol 1949;25:757-9.

2. Kantelip B, Satge D, Camilleri L, Chenard MP, De Riberolles C. Valvular cyst and atrioventricular canal in a child with trisomy 21. Ann Pathol 1994;14:101-7.

3. Eugene KWS, May LW, King TT, Sze KS. Blood cysts of the tricuspid valve. Ann Thorac Surg 1996;61:1012-3.

4. Arnold IR. Hubner PJ, Firmin RK. Blood filled cyst of the papillary muscle of the mitral valve producing severe left ventricular outflow tract obstruction. Br Heart J 1990;63:132-3.

5. Pasaoglu I, Dogan R, Demircin M, Bozer AY. Blood cyst of the pulmonary valve causing pulmonary stenosis. Am J Cardiol 1993;72:493-4.

6. Sakakibara S, Katsuhara K, Iida Y, Nishida H. Pulmonary subvalvular tumor. Dis Chest 1967;51:637-42. 